\title{
Accuracy of Functional Performance in Healthy Elderly Subjects, with Mild Cognitive Impairment and Alzheimer's Disease
}

\author{
Natalia Lemos Fransen ${ }^{1}$ \\ Orcid.org/0000-0001-6823-6317 \\ Maila Holz ${ }^{1}$ \\ Orcid.org/0000-0001-8648-4234 \\ Andressa Pereira ${ }^{2}$ \\ Orcid.org/0000-0002-2110-2095 \\ Rochele Paz Fonseca ${ }^{1}$ \\ Orcid.org/0000-0001-6767-8439 \\ Renata Kochhann ${ }^{*}, 1$ \\ Orcid.org/0000-0002-6328-8131
}

${ }^{1}$ Pontificia Universidade Católica do Rio Grande do Sul, Porto Alegre, RS, Brasil

${ }^{2}$ Universidade do Vale do Rio dos Sinos, São Leopoldo, RS, Brasil

\begin{abstract}
It is challenging to establish the continuum of cognitive and functional decline in normal to pathological aging. In this transition is the Mild Cognitive Impairment (MCI), defined by subtle impairment in cognition and functionality. When functional impairment increases, it meets the criteria for dementia. Thus, it is essential to determine an accurate diagnosis from the functional evaluation. The aim of this study was to compare functional performance through direct versus indirect assessments, verify the relationship between them, and evaluate the accuracy of it within the control group, MCI and Alzheimer's disease (AD) patients. Ninety subjects ( $n=27$ controls, $n=35 \mathrm{MCI}$ and $n=28 \mathrm{AD}$ ) participated in the study. We used the Activities of the Daily Living Questionnaire (ADL-Q) and the Direct Assessment of Functional Status (DAFS-R). MANCOVA was performed to compare the direct functional performance, and ROC curves were used to verify the diagnostic accuracy of the scales among groups. The performance of the direct assessment showed differences between the controls and MCI, and between MCI and AD subjects. Both scales showed differences between MCI and AD, and DAFS-R showed differences between controls and MCI. Thus, DAFS-R demonstrated better accuracy of functional performance in these groups.
\end{abstract}

Keywords: Functional performance, Aging, Mild Cognitive Impairment, Alzheimer's disease.

* Mailing address: Av. Ipiranga, 6681, prédio $11-9^{\circ}$ andar, sala 932, Porto Alegre, RS, Brazil 90619-900. Phone: (51) 33207742. E-mail: renata.kochhann@gmail.com

Agradecimentos: Ao conselho Nacional de Desenvolvimento Científico e Tecnológico (CNPq), Coordenação de Aperfeiçoamento de Pessoal de Nível Superior (Capes), Fundação de Amparo à Pesquisa do Estado do Rio Grande do Sul (FAPERGS). 


\section{Acurácia do Desempenho Funcional em Idosos Saudáveis, com Comprometimento Cognitivo Leve e Doença de Alzheimer}

\section{Resumo}

Estabelecer o continuum de declínio cognitivo e funcional no envelhecimento normal para o patológico é desafiador. Nesta transição está o Comprometimento Cognitivo Leve (CCL), definido por prejuízo sutil na cognição e funcionalidade. Quando o prejuízo funcional aumenta preenche critérios para demência. Assim, determinar a acurácia diagnóstica da avaliação funcional é imprescindível. Com isso o objetivo foi comparar o desempenho funcional através da avaliação direta versus indireta e avaliar a acurácia do desempenho destas avaliações entre controles, pacientes com CCL e com doença de Alzheimer (DA). Participaram 90 indivíduos ( $n=27$ controles, $n=35$ pacientes com CCL e $n=28$ com DA). Foram utilizadas a Activities of Daily Living Questionnaire (ADL-Q) e a Direct Assessment of Functional Status (DAFS-R). Foram realizadas MANCOVA para comparar o desempenho funcional direto entre os participantes e curvas ROC para verificar a acurácia diagnóstica das escalas entre os grupos. O desempenho da avaliação direta demonstrou diferenciar controles de CCL e CCL de DA. Ambas as escalas mostraram diferenciar CCL e DA, e a DAFS-R controles de CCL. Assim, a DAFS-R evidenciou melhor acurácia do desempenho funcional nestes grupos.

Palavras-chave: Desempenho funcional, envelhecimento, Comprometimento Cognitivo Leve, doença de Alzheimer.

\section{Precisión del Rendimiento Funcional en Personas Mayores Sanas, con Deterioro Cognitivo Leve y Enfermedad de Alzheimer}

\section{Resumen}

Establecer el deterioro cognitivo y funcional en el envejecimiento normal y de la enfermedad es desafiador. Esta transición es el Deterioro Cognitivo Leve (DCL), definido por deterioro sutil en la cognición y la funcionalidad. Cuando aumenta el deterioro funcional cumple con los criterios para la demencia. Por lo tanto, para determinar la exactitud diagnóstica de evaluación funcional es esencial. Por lo tanto, el objetivo fue comparar el rendimiento funcional a través de directa frente a la evaluación indirecta, verificar la relación de estas actuaciones, evaluar la exactitud de los resultados de estas evaluaciones entre los controles, los pacientes con DCL y enfermedad de Alzheimer (EA). Participaron 90 sujetos ( $n$ $=27$ controles, $n=35$ pacientes DCL y $n=28$ EA). Se utilizaron Activities of Daily Living Questionnaire (ADL-Q) y Direct Assessment of Functional Status (DAFS-R). Se realizaron MANCOVA para comparar el rendimiento funcional directo entre los participantes y las curvas ROC para verificar la precisión diagnóstica de las escalas entre los grupos. El rendimiento de la evaluación directa mostró diferenciar los controles de DCL, y DCL de EA. Ambas escalas mostraron diferenciar DCL y EA, y DAFS-R controles de DCL. Por lo tanto, DAFS-R mostró una mejor precisión del rendimiento funcional en estos grupos.

Palabras clave: Rendimiento funcional, envejecimiento, Deterioro Cognitivo Leve, enfermedad de Alzheimer.

Dementia caused by Alzheimer's disease (AD) has insidious onset and may lead to months or years of cognitive and functional decline (Albert et al., 2011; McKhann et al., 2011). The distinction between normal and pathological ag- ing is difficult to define, since it is characterized as a possible continuum. In this evolution, we highlight Mild Cognitive Impairment (MCI), in which cognitive impairments are already present, but with a subtle impact on daily life, af- 
fecting more complex activities of the individual without impairing their level of independence (Albert et al., 2011). Given this difficult definition between healthy and pathological aging, the diagnostic accuracy of direct versus indirect functional assessments is essential.

The onset of $\mathrm{AD}$ and MCI symptoms is presented by cognitive deficits, and can be amnestic or non-amnestic (Petersen et al., 2009). In non-domestic frameworks, deficits can be of language, attention, perception, agnosia, social cognition and/or executive functions, such as alteration of reasoning, planning, cognitive flexibility, inhibitory control, working memory, judgment, and problem solving (American Psychiatric Association [APA], 2014; McKhann et al., 2011). Due to cognitive impairment, the patient may present complaints from the outset when performing previously habitual tasks such as preparing meals, paying bills, and shopping (Frota et al., 2011).

One study demonstrated that people with $\mathrm{MCI}$ are 6.7 times more likely to develop $\mathrm{AD}$ than healthy elderly individuals (Boyle, Wilson, Aggarwal, Tang, \& Bennett, 2006). Elderly patients with MCI suffer a decrease in cognitive functioning at a faster rate than normal-aging individuals (Boyle et al., 2006). While MCI diagnostic criteria show functional preservation, studies suggest that patients with MCI may suffer with the complexity of daily living activities (DLA), such as coping with finances and skills related to purchases (Pereira, Oliveira, Diniz, Forlenza, \& Yassuda, 2010). Although in AD the impairment of DLA is greater than in patients with MCI (Marshall et al., 2011), there may be impairment in the daily functioning of the elderly with MCI when compared to their own previous performances (Farias et al., 2006).

Functional performance is the main differentiator between AD and MCI. The elderly with MCI, based on the diagnostic criteria, can, at most, present subtle impairment in more complex and / or instrumental daily activities (Albert et al., 2011; Teng, Becker, Woo, Cummings, \& Lu, 2010; Marshall et al., 2011). These complex functional activities include the ability to prepare a meal, perform housework, deal with finances, and administer medication. On the other hand, basic daily life activities that include self-care and the ability to perform personal hygiene, sphincter control and proper feeding are preserved (Chaves et al., 2011).

Functional evaluation is important for the diagnostic differentiation between early dementia and MCI. This evaluation can be indirect or direct. The indirect assessment is carried out through the report of an observer, using tools like scales and questionnaires. The direct assessment happens through observing and examining functional performance based on the simulation of daily life activities, in an ecological way (Lima-Silva et al., 2014; Pereira, Oliveira, et al., 2010). Both in clinical practice and in research the observer, or informant, is the main source of data, and he or she may underestimate or overestimate the patient's actual functional decline. This is because they are susceptible to biases caused by frames of humor, personality, negative feelings, physical fatigue, or informant burnout (Pereira, Oliveira, et al., 2010; Novelli, Nitrini, \& Caramelli, 2010). In addition, a direct assessment of performance in daily activities, in contrast to an assessment made by an informant, allows for better accuracy in the differentiation between healthy elderly, MCI and AD (Goldberg et al., 2010).

Performing a direct functional evaluation gains more relevancy when we consider that more and more elderly adults are living alone (Brazilian Institute of Geography and Statistics [IBGE], 2008; Department of Health and Human Services [DHHS], 2002). For this reason, they do not usually have a family member or caregiver who is present in your routine and might observe their functional impairments. This type of functional evaluation is necessary to avoid possible risks to these elderly adults.

Several scales and questionnaires were developed for the evaluation of basic and complex daily activities in individuals with dementia (Johnson, Barion, Rademaker, Rehkemper, \& Weintraub, 2004). In Brazil, some instruments for the indirect functional evaluation are validated and recommended for use in the diagnosis of dementia in AD (Chaves et al., 2011). They 
are: Informant Questionnaire on Cognitive Decline in the Elderly (IQCODE; Bustamante et al., 2003; Jorm \& Jacomb, 1989; Sanchez \& Lourenço, 2009); Disability Assessment for Dementia (DAD; Bahia et al., 2010; Gauthier et al., 1994); Activities of the Daily Living Questionnaire (ADL-Q; Johnson et al., 2004); and Bayer's Scale of Daily Life Activities (B-ADL; Folquitto et al., 2007; Hindmarch, Lehfeld, de Jongh, \& Erzigkeit, 1998; Mapi Research Institute, 1999).

The Activities of the Daily Living Questionnaire (ADL-Q) is a scale that evaluates both basic and complex (or instrumental) activities and is performed with family members or caregivers of elderly adults with suspicion of dementia (Medeiros \& Guerra, 2009). It evaluates six domains: self-care, social interaction, organization, planning, and social participation. The patient is observed by another person. Therefore, this assessment depends on an observer's report (Johnson et al., 2004). The only study found to evaluate patients with $\mathrm{MCI}$ and $\mathrm{AD}$ using ADLQ demonstrated a high test-retest reliability and good accuracy to detect a mild decline, as well as the more severe symptoms of disease progression (Johnson et al., 2004).

The Performance-Based Skills Assessment (Goldberg et al., 2010) and the Direct Assessment of Functional Status (DAFS) are considered direct functional assessments, and are applied to patients with complaints and suspicion of dementia (Loewenstein et al., 1989). DAFS was developed to evaluate a variety of functional abilities, both basic and complex, required for independent living in elderly adult patients with and without cognitive impairment. The main objective of DAFS is to perform a closer assessment of the actual daily performance of older adults (Loewenstein et al., 1989; Zanetti, Frisoni, Rozzini, Bianchetti, \& Trabucchi, 1998).

The DAFS evaluates six domains: temporal orientation, communication, ability to handle money and shopping, personal hygiene, and ability to dress and feed independently (Pereira, Oliveira, et al., 2010). The validation of DAFS$\mathrm{R}$ for Brazilian culture was performed through a sample of healthy elderly, MCI and AD patients. In this study, a significant difference was observed in $\mathrm{AD}$ patients in relation to healthy elderly and MCI, showing lower performance in orientation, communication skills and time perception. Dressing skills, personal hygiene and feeding presented lower relationships compared to the other subcategories. This may have occurred because the tasks involved in these domains are performed automatically, so these tasks may have limited abilities to differentiate these groups from older adults. The DAFS has great accuracy in discriminating the healthy elderly of patients with AD (Loewenstein et al., 1989) and also differentiates elderly with MCI from healthy elderly people (Pereira, Oliveira, et al., 2010).

Therefore, it can be observed that the direct evaluation of the functional performance presented good discriminative power among healthy elderly adults, patients with MCI and patients with AD (Pereira, Oliveira, et al., 2010). However, in the validation study for Brazil was no specific concern to include only patients with mild stage dementia. The inclusion of patients in more advanced stages of dementia allows for greater differentiation between the groups. Furthermore, we did not find a study that performed an evaluation of the accuracy of functional domains of direct evaluation. Our study also had as objectives to evaluate the accuracy of the total scores of direct and indirect evaluations among elderly adults with MCI, with AD and controls; and the accuracy of the domains of direct evaluation between controls versus MCI and MCI versus $\mathrm{AD}$, in domains that demonstrate difference in performances between these groups.

\section{Method}

\section{Participants}

The sample was composed by 90 elderly adults, divided into three groups: $n=27$ controls, $n=35$ patients with MCI and $n=28$ patients with mild AD. The following inclusion / exclusion criteria were used for the different groups: elderly control adults, elderly adults with MCI and elderly adults with AD. Inclusion criteria for all groups: individuals with 55 years of age or older and had at least one full year of formal edu- 
cation. MCI patients had to meet the diagnostic criteria for Mild Cognitive Impairment (Winblad et al., 2004); individuals with AD had to meet the current criteria for Alzheimer's disease (Frota et al., 2011). Only patients with a history of concomitant vascular disease were included as possible AD. Patients with AD had to present a mild severity stage assessed by the Clinical Dementia Rating Scale (CDR) $=1$ (Chaves et al., 2007; Hughes, Berg, Danziger, Coben, \& Martin, 1982) and Mini State Examination Mental (MMSE)> 14 points (Reisberg et al., 2011), or MMSE $>14$ and ADL-Q $<66$ points (Medeiros \& Guerra, 2009).

Participants with sensory disturbances (auditory and / or visual) without correction were excluded for all groups. The following were also excluded: patients with current or previous history of alcohol abuse, illicit drugs, and aphasic symptoms that would make evaluation impossible. For the control group and the MCI, participants with a history of current neurological or psychiatric conditions were excluded, as well as those with presence of current depressive symptoms, greater than or equal to mild (GDS $\leq 6)$ for controls and greater than mild for MCI, evaluated by the Geriatric Depression Scale (GDS-15) - (Almeida \& Almeida, 1999; Yesavage et al., 1983); MMSE $\leq 22$, if education between 1 and 5 years, MMSE $\leq 23$, if education between 6 and 11 years, $M M S E \leq 24$, if education $\geq 12$ years (Chaves, \& Izquierdo, 1992; Folstein, Folstein, \& McHugh, 1975; Kochhann, Varela, Lisboa, $\&$ Chaves, 2010). For the control group, participants with an intellectual level equal to or lower than the borderline level examined by the WASI scale were also excluded (Trentini, Yates, \& Heck, 2014; Wechsler, 1999).

The initial study sample consisted of 123 individuals; of these, 18 patients were excluded because they presented moderate to severe dementia, five because they presented cognitive impairment due to another neurological disease other than AD (e.g. Parkinson's disease, TBI, alcoholic dementia), nine because of their current psychiatric disorder, and one subject for presenting borderline IQ.

\section{Ethical Aspects and Procedures}

The present study was carried out as part of a bigger project approved by the Research Ethics Committee of the Pontifical Catholic University of Rio Grande do Sul (PUCRS), number $657.955 / 14$ and by the Ethics Committee of the Clinics Hospital of Porto Alegre (Hospital de Clínicas de Porto Alegre [HCPA]), number 140368. Patients were selected from the Dementia Outpatient Clinic of the HCPA. We also reached out to patients via television, radio and Internet. All participants signed and received a copy of the Term of Informed Consent. All elderly adult participants and their relatives / caregivers were evaluated individually in quiet rooms and free of external stimuli. The evaluation was composed of two sessions of approximately two hours each, following the same order of the instruments for all participants. The CDR scale was not applied during this study, because it is routinely used in the care of patients from the HCPA Dementia Outpatient Clinic. All medical records were assessed, and only patients with a diagnosis of AD dementia with a stage classified as mild (CDR $=$ 1) were invited to participate in the study.

\section{Instruments}

The instruments were divided between sample characterization instruments and functional evaluation instruments.

Characterization Instruments. The sociocultural questionnaire and health aspects for elderly adults is a semi-structured questionnaire that includes questions about gender; age; education (years); frequency of reading and writing habits through scores: everyday (4 points), weekly ( 3 points), monthly ( 2 points), rarely (1 point) and never (zero points), with a total score of 28 points; use of medications; description of the onset and progression of forgetfulness symptoms; or functional impairment. It also evaluates the socioeconomic level according to the rules of the, Brazilian Criteria of Economic Classification, provided by the Brazilian Association of Research Companies (ABEP, 2014), considering the strata A (45 to 100 points), B1 (38 to 
44 points), B2 (29 to 37 points), C1 (23 to 28 points), C2 (17 to 22 points) and SD (0 to 16 points), among other clinical and sociodemographic variables.

The other instruments are included in the sample description and were used for the evaluation of the inclusion and exclusion criteria of the participants. In addition, all participants underwent a broad neuropsychological evaluation of verbal and visual episodic memory, semantic memory, prospective memory, working memory, assessment of verbal and visuomotor initiation and inhibition capacity, verbal fluency, and comprehension (Fransen et al., in press).

\section{Functional Evaluation Instruments}

The Activities of Daily Living Questionnaire (ADL-Q; Johnson et al., 2004; Medeiros $\&$ Guerra, 2009) is an instrument that evaluates the routine functioning of the patient through information provided by a family member or caregiver. It allows to evaluate basic and instrumental daily life activities (domains of self-care, interaction, intellectual activity, organization / planning, social participation and feeding). The total score varies from 0 to 100 . Classification is as follows: from 0 to 33: no losses or slight losses; from 34 to 66: moderate losses; and over 66 serious losses. The adapted version for Brazil presented good reliability through Cronbach's alpha of 0.759 (Medeiros, \& Guerra, 2009).

The Direct Assessment of Functional Status - Revised (DAFS-R; Loewenstein et al., 1989; Pereira, Oliveira, et al., 2010) is an instrument based on simulations of basic and instrumental daily life activities of the elderly adult in which the participant must perform activities similar to his or her routine. The DAFS-R is an abbreviated version that evaluates seven different domains of functional abilities. The total score ranges from 0 to 105 , the higher the score, the better the performance. The domains evaluated are temporal orientation (16 points); skills needed for communication (14 points); dealing with finances (32 points); buying skills (20 points); skills needed to pack / dress (13 points) and eat domain (10 points). The adapted version for
Brazil presented good sensitivity $=0.995$ and specificity $=0.995$ to identify MCI and DA (Pereira, Yassuda, et al., 2010).

\section{Data Analysis}

We used Statistical Package for the Social Sciences (SPSS), version 17.0, for data analysis. The variables analyzed did not present a normal distribution. Thus, we performed the non-parametric Kruskal Wallis test and the Chi-square to characterize the sample. After that, we conducted a MANCOVA, controlling for age and education, the frequency of reading and writing habits, and the socioeconomic level score, to verify the direct functional performance of the participants in the groups (Control versus MCI and $\mathrm{MCI}$ versus $\mathrm{AD}$ ), including the overall score and domains. A Spearman correlation analysis was performed between ADL-Q and DAFS-R in order to verify the possible association between them. Finally, to check the diagnostic accuracy of the functional scales in ADL-Q and DAFS-R between the controls versus $\mathrm{MCI}$ and $\mathrm{MCI}$ versus $\mathrm{AD}$ group, we implemented receiver operating characteristic (ROC) curves. For all analyses, differences with significance level $p \leq .05$ were considered significant.

\section{Results}

The sociodemographic and clinical data of the sample can be observed in Table 1. There was no difference in gender distribution. In the other variables, it can be observed that the patients with $\mathrm{AD}$ were older, had less education, had lower economic class score, less reading and writing habits, and greater cognitive impairment.

In the MANCOVA analyses to verify the direct functional performance of the participants in the groups (control versus MCI and MCI versus $\mathrm{AD}$ ), including the general and domains score, only the general score and the domain of money skills differentiated controls of MCI. The MCI group had lower scores than the control group. In the comparison between $\mathrm{MCI}$ and $\mathrm{AD}$, both general score and domains differentiated these 
Table 1

Socio-Demographic and Clinical Data

\begin{tabular}{|c|c|c|c|c|c|}
\hline Variables & $\begin{array}{l}\text { Controls } \\
(n=27)\end{array}$ & $\begin{array}{c}\text { MCI } \\
(n=35)\end{array}$ & $\begin{array}{c}\mathrm{AD} \\
(n=28)\end{array}$ & $p$ & $\begin{array}{l}\text { Post-Hoc } \\
\text { analysis }\end{array}$ \\
\hline Age $(m \pm s d)$ & $68.07 \pm 5.57$ & $69.34 \pm 7.04$ & $75.07 \pm 6.65$ & .001 & $\mathrm{C}, \mathrm{MCI}<\mathrm{AD}$ \\
\hline Education $(m \pm s d)$ & $14.19 \pm 5.57$ & $10.26 \pm 4.60$ & $6.71 \pm 5.16$ & $<.001$ & $\mathrm{C}>\mathrm{MCI}>\mathrm{AD}$ \\
\hline Socioeconomic level $(m \pm s d)$ & $36.08 \pm 12.17$ & $32.34 \pm 10.14$ & $27.93 \pm 6.76$ & .038 & $\mathrm{C}>\mathrm{AD}$ \\
\hline $\begin{array}{l}\text { Frequency of reading and writing } \\
\text { score }(m \pm s d)\end{array}$ & $16.22 \pm 4.91$ & $11.97 \pm 6.35$ & $5.79 \pm 4.22$ & $<.001$ & $\mathrm{C}>\mathrm{MCI}>\mathrm{AD}$ \\
\hline $\operatorname{MMSE}(m \pm s d)$ & $28.41 \pm 2.39$ & $26.11 \pm 3.47$ & $21.04 \pm 4.01$ & $<.001$ & $\mathrm{C}>\mathrm{MCI}>\mathrm{A}$ \\
\hline GDS-15 $(m \pm s d)$ & $1.59 \pm 1.86$ & $2.06 \pm 2.26$ & $4.96 \pm 3.46$ & $<.001$ & $\mathrm{C}, \mathrm{MCI}<\mathrm{AD}$ \\
\hline Female gender - $n(\%)$ & $20(74.1)$ & $25(71.4)$ & $22(78.6)$ & .811 & - \\
\hline
\end{tabular}

Note. $p \leq .05$ is considered significant. MMSE $=$ Mini Mental State Examination; GDS-15 = Geriatric Depression Scale; $\mathrm{C}=$ Controls; $\mathrm{MCI}=$ Mild Cognitive Impairment; $\mathrm{AD}=$ dementia of Alzheimer's disease. In bold is highlighted the values with significant difference.

Table 2

Comparison of Direct Functional Performance between Groups

\begin{tabular}{lcccccc}
\hline \multicolumn{1}{c}{ Variables } & \multicolumn{3}{c}{ Controls X MCI } & \multicolumn{3}{c}{ MCI X AD } \\
\cline { 2 - 7 } & $F$ & $p$ & $n^{2}$ partial & $F$ & $p$ & $n^{2}$ partial \\
\hline Temporal orientation & 1.045 & .311 & 0.019 & 29.748 & $<.001$ & 0.347 \\
Skills needs for comunication & 0.041 & .840 & 0.001 & 4.400 & $\mathbf{. 0 4 0}$ & 0.073 \\
Dealing with finances & 6.076 & $\mathbf{. 0 1 7}$ & 0.099 & 15.774 & $<.001$ & 0.220 \\
Buying skills & 0.957 & .332 & 0.170 & 13.906 & $<.001$ & 0.199 \\
Skills needs for pack/dress & 0.037 & .848 & 0.001 & 8.088 & $\mathbf{. 0 0 6}$ & 0.126 \\
Eat domain & - & - & - & 2.007 & .162 & 0.035 \\
DAFS-R geral score & 4.747 & $\mathbf{. 0 3 4}$ & 0.079 & 27.910 & $<.001$ & 0.333 \\
\hline
\end{tabular}

Note. $p \leq .05$ is considered significant. DAFS-R=Direct Assessment of Functional Status - Revised $;$ MCI = Mild Cognitive Impairment; $\mathrm{AD}=$ dementia of Alzheimer's disease. In bold is highlighted the values with significant difference.

groups, and the AD group had lower scores than the MCI group, except for the eat domain, in which there were no differences between the groups (Table 2).

Spearman's correlation analysis showed that the total DAFS-R score and the total ADL-Q score had a strong and negative association (rho $=-0.743, p<.001)$. Thus, Table 3 shows the best cut-off points observed, maintaining the balance between sensitivity and specificity for the indirect and direct functional evaluation scales. It can be observed that both scales have greater accuracy between the MCI and AD groups. However, DAFS-R showed better accuracy in differentiating MCI from controls than ADL-Q. For the DAFS-R scale, accuracy analyses were also performed for the domains that showed a difference in performance between controls versus $\mathrm{MCI}$ and $\mathrm{MCI}$ versus $\mathrm{AD}$ in the MANCOVA analysis. 
Table 3

Cut-Off Points of DAFS - R and ADL - Q

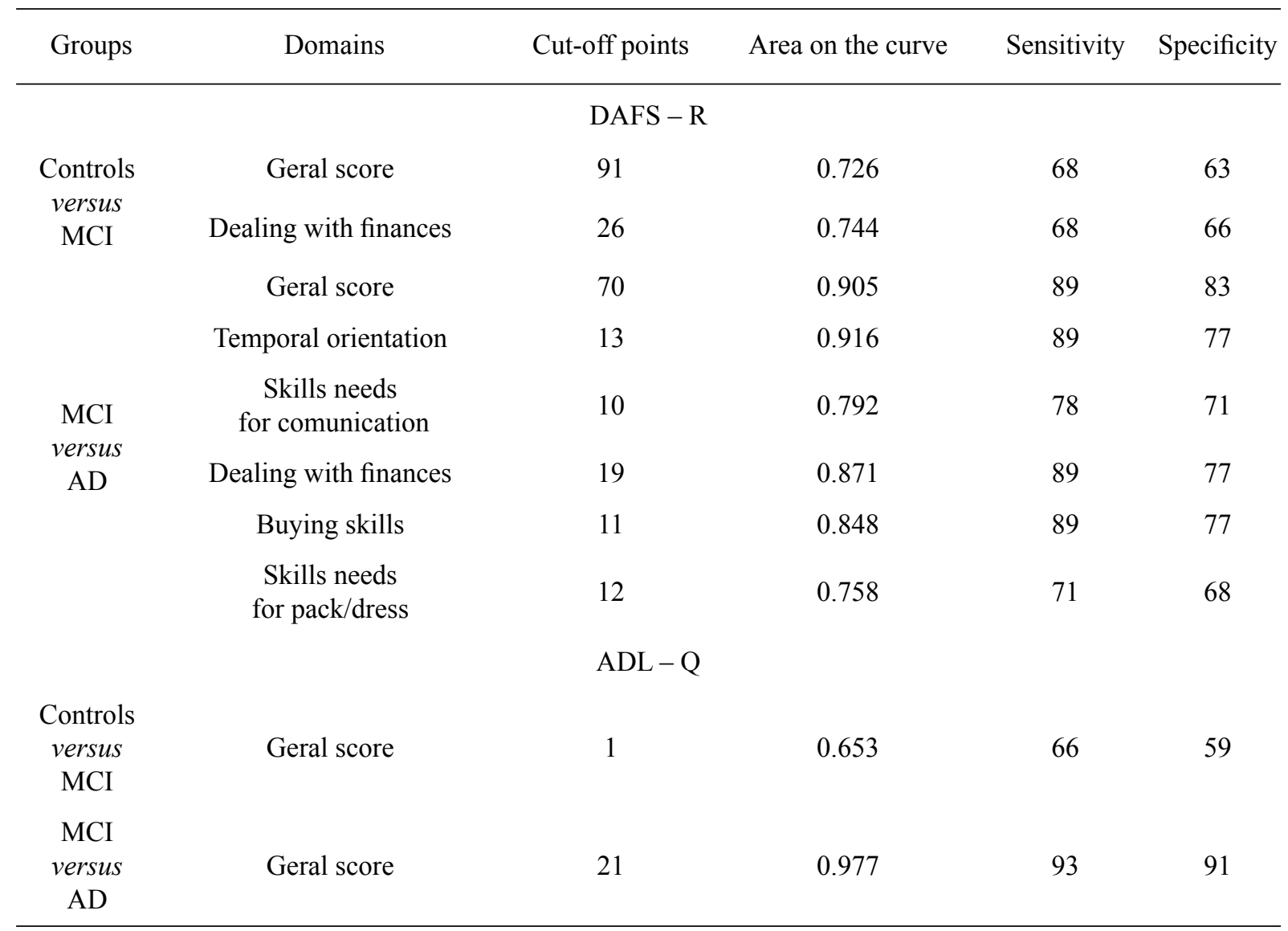

Note. $p \leq .05$ is considered significant. ADL-Q $=$ Activities of Daily Living Questionnaire; DAFS-R= Direct Assessment of Functional Status - Revised; MCI = Mild Cognitive Impairment; AD = dementia of Alzheimer's disease.

\section{Discussion}

The aim of the study was to compare the accuracy of the direct assessment scores by DAFS and indirect ADL-Q scores among elderly adults with $\mathrm{MCI}$, with $\mathrm{AD}$ and controls, and to ascertain the accuracy of the domains of direct evaluation between Controls versus MCI and MCI versus DA. The comparison of the performance of the direct evaluation represented by the DAFS instrument, controlling the sociodemographic variables, showed that the total score differentiates controls from MCI and MCI from AD. However, although almost all domains differ between the $\mathrm{MCI}$ and $\mathrm{AD}$ groups, it can only be observed that money skills differentiated the MCI and control groups. This result indicates that coping skills may be the first sign of decline in the very subtle functionality that is already present in MCI frameworks. This suggests that individuals with MCI have an increased risk of developing dementia (Boyle et al., 2006), precisely because they already begin to show small declines in instrumental abilities that they did not previously have.

The evaluation by the DAFS, in addition to having differentiated MCI from controls, replicating previous studies (Pereira, Yassuda, et al., 2010; Puente, Terry, Faraco, Brown, \& Miller, 2014) also presented excellent accuracy to differentiate MCI from AD. Moreover, it can be observed that the direct evaluation of the functionality presents better accuracy than an indirect evaluation. This is probably due to capturing more information about the overall severity of dementia (Farias, Harrell, Neumann, \& Houtz, 2003).

In addition, the results are in agreement with literature that shows differences of control group from MCI in the domain of money skills (Pereira, 
Oliveira, et al., 2010; Razani et al., 2011); however, the study by Pereira, Oliveira, et al. (2010) found a difference in purchasing skills. Yet, it is worth mentioning that this study used as an exclusion criterion scores lower than 10 points in the MMSE and included AD patients with mild or moderate stages; in comparison with the present study which excluded patients with MMSE lower than 15 points and only included AD patients at a mild stage. Thus, the objective of the present study was to enable the differentiation between controls and MCI and between MCI and $\mathrm{AD}$, in order to more accurately evaluate the functional decline present in the frames of cognitive neurodegeneration.

Studies have shown that elderly adults with $\mathrm{AD}$ showed greater losses in the domains of financial skills, shopping, temporal orientation and communication skills in relation to the healthy elderly and MCI (Goldberg et al., 2010; Pereira, Oliveira, et al., 2010). The findings showed similar results by direct evaluation: older adults with $\mathrm{AD}$ presented worse performance than patients with MCI in the total score and in all domains, except for the alimentary domain. Regarding the differentiation between $\mathrm{MCI}$ and controls, only the DAFS differentiated these elderly adults. Thus, this type of direct functional evaluation proves to be important for the differentiation of these pathologies.

The perceived advantage in directly patientbased information is that they are free of possible distortions by the caregiver's assessment and of possible underestimation and overestimation of their functionality (Goldberg et al., 2010; Ready, Ott, \& Grace, 2004). They are not susceptible to biases caused by humor, personality or burnout of informants (Pereira, Oliveira, et al., 2010). In addition, elderly adults who reside alone may not have a reliable informant because they do not have an adequate contact frequency that allows an accurate report of functional performance, so they do not have a family member who is in their routine to observe the functional impairments. One study showed that caregivers who spent less than 20 hours per week with older adults were inclined to make at least one judgment error (Loewenstein et al., 2001), which emphasizes the need for direct functional evaluation in elderly people living alone.

According to the DHHS (2002), older adults have the desire to maintain independence and reside alone. With increasing life expectation, the percentage of elderly individuals living alone increases proportionally (DHHS, 2002; IBGE, 2008). Thus, due to the progressive increase of the elderly living alone there is a need for a direct functional evaluation, enabling better monitoring and early diagnosis in order to provide adequate treatment for dementia.

One limitation was the inclusion of the ADL-Q scale in the main objective of the study. This was because the scale belonged to the instruments that evaluated the inclusion criteria for the sample (helping in the differentiation between MCI and AD), but at the same time it was performed as an indirect evaluation accuracy criterion: functionality. However, this was done because no article with ADL-Q cutoff points was found. The validation study of the ADL-Q scale demonstrated that it is a sensitive tool to the detection of mild decline as well as more serious damage to disease progression (Johnson et al., 2004). Still, this study did not include control group and MCI in its sample (Johnson et al., 2004). In the present study, although ADL-Q demonstrated good accuracy to discriminate $\mathrm{MCI}$ and $\mathrm{AD}$, it did not discriminate for differentiation between control and MCI elderly adults. It is important to highlight that the ADL-Q and DAFS scores are opposites, that is, a better performance in the ADL-Q will yield a score close to or equal to zero. In the DAFS, on the other hand, a score of zero indicates poor performance. This aspect implies to have little or almost no variability in the score of the ADL-Q scale between controls and MCI. In general, this is a characteristic of scales that evaluate functionality through an informant's report.

Thus, it can be concluded that direct evaluation of the functional performance of patients presents a better diagnostic accuracy between elderly control adults and MCI and between elderly with MCI and AD. This type of instrument proves to be indispensable in the evaluation of elderly people who do not have 
informants or who do not have a reliable report. The importance of its use also in the context of public health is emphasized, with the objective of increasing the diagnostic accuracy. However, studies that investigate the functional levels for each MCI subtype are recommended. In addition, longitudinal studies are suggested to evaluate the functional continuum of the subgroups that were evaluated in the present study.

\section{Authors' Contributions}

Substantial contribution in the concept and design of the study: Natalia Lemos Fransen, Rochele Paz Fonseca, Renata kochhann.

Contribution to data collection: Natalia Lemos Fransen, Maila Holz, Andressa Pereira.

Contribution to data analysis and interpretation: Natalia Lemos Fransen, Maila Holz, Andressa Pereira, Renata kochhann.

Contribution to manuscript preparation: Natalia Lemos Fransen, Maila Holz, Andressa Pereira, Renata kochhann.

Contribution to critical revision, adding intelectual content: Rochele Paz Fonseca.

\section{Conflicts of interest}

The authors declare that they have no conflict of interest related to the publication of this manuscript.

\section{References}

Albert, M. S., Dekosky, S. T., Dickson, D., Dubois, B., Feldman, H. H., Fox, N. C., ...Phelps, C. H. (2011). The diagnosis of mild cognitive impairment due to Alzheimer's disease: Recommendations from the National Institute on Aging-Alzheimer's Association workgroups on diagnostic guidelines for Alzheimer's disease. Alzheimer's \& Dementia, 7, 270-279. doi: 10.1016/j.jalz.2011.03.008

Almeida, O. P., \& Almeida, S. A. (1999). Confiabilidade da versão brasileira da Escala de Depressão em Geriatria (GDS) versão reduzida. Arquivos de Neuro-Psiquiatria, 57(2B), 421-426. doi: 10.1590/S0004-282X1999000300013

American Psychiatric Association. (2014). Manual diagnóstico e Estatístico de Transtornos Mentais: DSM-5. Porto Alegre, RS: Artmed
Bahia, V., S., Carthery-Goulart, M., T., Novelli, M., M., Kato-Narita, E. M., Areza-Fegyveres, R., Caramelli, P., \& Nitrini, R. (2010). Functional disability in Alzheimer disease: a validation study of the Brazilian version of Disability Assessment for Dementia (DAD-Br). Alzheimer Disease and Associated Disorder, 24, 291-295. doi: 10.1097/WAD.0b013e3181cfc878

Boyle, P. A., Wilson, R. S., Aggarwal, N. T., Tang, Y., \& Bennett, D. A. (2006). Mild cognitive impairment Risk of Alzheimer disease and rate of cognitive decline. Neurology, 67(3), 441-445. doi: 10.1212/01.wnl.0000228244.10416.20

Brazilian Association of Research Companies. (2014). Critério de Classificação Econômica Brasil. Retrieved from http://www.abep.org

Brazilian Institute of Geography and Statistics. (2008). Síntese de Indicadores Sociais: Uma análise das condições de vida da população brasileira. Estudos e Pesquisas: Informação Demográfica e Socioeconômica, 23.

Bustamante, S., E., Z., Bottino, C., M., C., Lopes, M., A., Azevedo, D., Hototian, S. R., Litvoc, J., \& Jacob, W., Filho. (2003). Instrumentos combinados na avaliação de demência de idosos. Arquivos de Neuropsiquiatria, 61, 601606. doi: http://dx.doi.org/10.1590/S0004282X2003000400014

Chaves, M. L. F., \& Izquierdo, I. (1992). Differential diagnosis between dementia and depression: A study of efficiency increment. Acta Neurologica Scandinavica, 85(6), 378-382. doi: 10.1111/ j.1600-0404.1992.tb06032.x

Chaves, M. L. F., Camozzato, A. L., Godinho, C., Kochhann, R., Schuh, A., De Almeida, V. L., \& Kaye, J. (2007). Validity of the clinical dementia rating scale for the detection and staging of dementia in Brazilian patients. Alzheimer Disease \& Associated Disorders, 21(3), 210217. doi: 10.1097/WAD.0b013e31811ff2b4

Chaves, M. L., Godinho, C. C., Porto, C. S., Mansur, L., Carthery-Goulart, M. T., Yassuda, M. S., \& Beato, R. (2011). Doença de Alzheimer: Avaliação cognitiva, comportamental e funcional. Dementia \& Neuropsychologia, 5(Suppl 1).

Department of Health and Human Services. (2002). Annual Report. Retrieved from https://www. acl.gov/sites/default/files/about-acl/2017-04/ AOA_2002_AnnualReport.pdf 
Farias, S. T., Harrell, E., Neumann, C., \& Houtz, A. (2003). The relationship between neuropsychological performance and daily functioning in individuals with Alzheimer's disease: Ecological validity of neuropsychological tests. Archives of Clinical Neuropsychology, 18(6), 655-672. doi: 10.1016/S0887-6177(02)00159-2

Farias, S. T., Mungas, D., Reed, B. R., Harvey, D., Cahn-Weiner, D., \& DeCarli, C. (2006). $\mathrm{MCI}$ is associated with deficits in everyday functioning. Alzheimer Disease and Associated Disorders, 20(4), 217. doi: 10.1097/01. wad.0000213849.51495.d9

Folquitto, J., C., Bustamente, S., E., Z., Barros, S., B., Azevedo, D., Lopes, M. A., Hototian, S. R., ...Bottino, C. M. C. (2007). The Bayer Activities of daily living scale (B-ADL) in the differentiation between mild to moderate dementia and normal aging. Revista Brasileira de Psiquiatria, 29, 350-353. doi: http://dx.doi. org/10.1590/S1516-44462006005000037

Folstein, M. F., Folstein, S. E., \& McHugh, P. R. (1975). "Mini-mental state": A practical method for grading the cognitive state of patients for the clinician. Journal of Psychiatric Research, 12(3), 189-198. doi: 10.1016/0022-3956(75)90026-6

Fransen, N., Holz, M., Tarrasconi, M., Candemil, C., Fonseca, R.P., \& Kochhann, R. (in press).Fatores cognitivos como preditores da funcionalidade no contínuo de comprometimento cognitivo no envelhecimento: Memória de trabalho e memória episódica verbal.

Frota, N. A. F., Nitrini, R., Damasceno, B.P., Forlenza, O., Dias-Tosta, E., da Silva, A. B., ...Magaldi, R. M. (2011). Critérios para o diagnóstico de doença de Alzheimer. Dementia \& Neuropsychologia, 5(Suppl. 1), 5-10.

Gauthier, L., Gélinas, I., McIntyre, M., Gauthier, S., Laberge, H., \& Dauphinee, S., W. (1994). Disability Assessment for Dementia (DAD) user's guide.

Goldberg, T. E., Koppel, J., Keehlisen, L., Christen, E., Dreses-Werringloer, U., Conejero-Goldberg, C., \& Davies, P. (2010). Performance-based measures of everyday function in mild cognitive impairment. American Journal of Psychiatry, 167(7), 845-853. doi: 10.1176/appi. ajp.2010.09050692
Hindmarch, I., Lehfeld, H., de Jongh, P., Erzigkeit, H. (1998). The Bayer Activities of Daily Living Scale (B-ADL). Dementia and Geriatric Cognitive Disorders, 9(2), 20-26.

Hughes, C. P., Berg, L., Danziger, W. L., Coben, L. A., \& Martin, R. (1982). A new clinical scale for the staging of dementia. The British Journal of Psychiatry, 140(6), 566-572. doi: 10.1192/ bjp.140.6.566

Johnson, N., Barion, A., Rademaker, A., Rehkemper, G., \& Weintraub, S. (2004). The Activities of Daily Living Questionnaire: A validation study in patients with dementia. Alzheimer Disease \& Associated Disorders, 18(4), 223-230.

Jorm, A. F., \& Jacomb, P. A. (1989). The Informant Questionnaire on Cognitive Decline in the Elderly (IQCODE): Socio-demographic correlates, reliability, validity and some norms. Psychological Medicine, 19, 1015-1022.

Kochhann, R., Varela, J. S., Lisboa, C. S., \& Chaves, M. L. F. (2010). The Mini Mental State Examination: Review of cutoff points adjusted for schooling in a large Southern Brazilian sample. Dementia \& Neuropsychologia, 35-41.

Lima-Silva, T., B., Bahia, V., S., Carvalho, V., A., Guimarães, H., C., Caramelli, P., Balthazar, M., L., F., ...Yassuda, M. S. (2014). Direct and Indirect Assessments of Activities of Daily Living in Behavioral Variant Frontotemporal Dementia and Alzheimer Disease. Journal of Geriatric Psychiatry and Neurology, 28, 1-8. doi: 10.1177/0891988714541874

Loewenstein, D. A., Amigo, E., Duara, R., Guterman, A., Hurwitz, D., Berkowitz, N., Wilkie, F., ... Eisdorfer, C. (1989). A new scale for the assessment of functional status in Alzheimer's disease and related disorders. Journal of Gerontology, 44(4), 114-121. doi: https://doi.org/10.1093/ geronj/44.4.P114

Loewenstein, D. A., Argüelles, S., Bravo, M., Freeman, R. Q., Argüelles, T., Acevedo, A., \& Eisdorfer, C. (2001). Caregivers' Judgments of the Functional Abilities of the Alzheimer's Disease Patient a Comparison of Proxy Reports and Objective Measures. The Journals of Gerontology Series B: Psychological Sciences and Social Sciences, 56(2), 78-84. 
Mapi Research Institute. (1999). Cultural Adaptation of the Bayer Activities of Daily Living Scale (B$A D L)$ into Brazilian Portuguese (Report). Lyon, France: Author.

Marshall, G. A., Rentz, D. M., Frey, M. T., Locascio, J. J., Johnson, K. A., Sperling, R. A., \& Alzheimer's Disease Neuroimaging Initiative. (2011). Executive function and instrumental activities of daily living in mild cognitive impairment and Alzheimer's disease. Alzheimer's \& Dementia, 7(3), 300-308. doi: 10.1016/j.jalz.2010.04.005

McKhann, G. M., Knopman, D. S., Chertkow, H., Hyman, B. T., Jack, C. R., Kawas, C. H., Klunk, W. E., ...Mohs, R. C. (2011). The diagnosis of dementia due to Alzheimer's disease: Recommendations from the National Institute on Aging-Alzheimer's Association workgroups on diagnostic guidelines for Alzheimer's disease. Alzheimer's \& Dementia, 7(3), 263-269. doi: 10.1016/j.jalz.2011.03.005

Medeiros, M. E. D., \& Guerra, R. O. (2009). Tradução, adaptação cultural e análise das propriedades psicométricas do Activities of Daily Living Questionnaire (ADLQ) para avaliação funcional de pacientes com a doença de Alzheimer. Revista Brasileira Fisioterapia, 13(3), 257-66.

Novelli, M. M. P. C., Nitrini, R., \& Caramelli, P. (2010). Cuidadores de idosos com demência: Perfil sociodemográfico e impacto diário. Revista de Terapia Ocupacional da Universidade de São Paulo, 21(2), 139-147.

Pereira, F. S., Oliveira, A. M., Diniz, B. S., Forlenza, O. V., \& Yassuda, M. S. (2010). Cross-cultural adaptation, reliability and validity of the DAFS$\mathrm{R}$ in a sample of Brazilian older adults. Archives of clinical neuropsychology, 25(4), 335-343. doi: 10.1093/arclin/acq029

Pereira, F. S., Yassuda, M. S., Oliveira, A., Diniz, B. S., Radanovic, M., Talib, L. L., Gattaz, W. F., \& Forlenza, O. V. (2010). Profiles of functional deficits in mild cognitive impairment and dementia: benefits from objective measurement. Journal of the International Neuropsychological Society, 16(02), 297-305. doi: 10.1017/ S1355617709991330

Petersen, R., C., Roberts, R., O., Knopman, D., Boeve, B. F., Geda, Y. E., Ivnik, R. J., ...Jack, C. R., Jr. (2009). Mild cognitive impairment: Ten years later. Archives of Neurology, 66, 14471455. doi: 10.1001/archneurol.2009.266

Puente, A. N., Terry, D. P., Faraco, C. C., Brown, C. L., \& Miller, L. S. (2014). Functional impairment in mild cognitive impairment evidenced using performance-based measurement. Journal of Geriatric Psychiatry and Neurology, 27(4), 253-258. doi: 10.1177/0891988714532016

Razani, J., Bayan, S., Funes, C., Mahmoud, N., Torrence, N., Wong, J., ... Josephson, K. (2011). Patterns of deficits in daily functioning and cognitive performance of patients with Alzheimer disease. Journal of Geriatric Psychiatry and Neurology, 24(1), 23-32. doi: 10.1177/0891988710390812

Ready, R. E., Ott, B. R., \& Grace, J. (2004). Patient versus informant perspectives of quality of life in mild cognitive impairment and Alzheimer's disease. International Journal of Geriatric Psychiatry, 19(3), 256-265. doi: 10.1002/gps.1075

Reisberg, B., Jamil, I. A., Khan, S., Monteiro, I., Torossiani, C., Ferris, S., ...Wegiels, J. (2011). Staging Dementia. In J. R. M. Copeland, M. T. Abou-Saleh, \& D. G. Blazer (Eds.), Principles and Practice of Geriatric Psychiatry ( $3^{\text {rd }}$ Ed.). Hoboken, NJ: John Wiley \& Sons.

Sanchez, M., A., \& Lourenço, R., A. (2009). Informant Questionnaire on Cognitive Decline in the Elderly (IQCODE): Cross-cultural adaptation for use in Brazil. Cadernos de Saúde Pública, $25,1455-1465$.

Trentini, C. M., Yates, D. B., \& Heck, V. S. (2014). WASI - Escala Wechsler Abreviada de Inteligência. São Paulo, SP: Pearson.

Wechsler, D. (1999). Wechsler Abbreviated Scale of Intelligence. San Antonio, TX: Pearson.

Winblad, B., Palmer, K., Kivipelto, M., Jelic, V., Fratiglioni, L., Wahlund, L.-O., ...Petersen, R. C. (2004). Mild cognitive impairment - Beyond controversies, towards a consensus: report of the International Working Group on Mild Cognitive Impairment. Journal of Internal Medicine, 256(3), 240-246.

Yesavage, J. A., Brink, T. L., Rose, T. L., Lum, O., Huang, V., Adey, M., \& Leirer, V. O. (1983). Development and validation of a geriatric depression screening scale: A preliminary report. Journal of Psychiatric Research, 17(1), $37-49$. 
Zanetti, O., Frisoni, G. B., Rozzini, L., Bianchetti,

Received: $19 / 05 / 2017$ A., \& Trabucchi, M. (1998). Validity of direct

$1^{\text {st }}$ revision: 03/11/2017 assessment of functional status as a tool for measuring Alzheimer's disease severity. Age and Accepted: 16/11/2017 Ageing, 27(5), 615-622. 